\title{
Effects of atomic ordering on the elastic properties of TiN- and VN-based ternary alloys
}

\author{
Daniel Edström, Davide G. Sangiovanni, Lars Hultman and Valeriu Chirita
}

\section{Linköping University Post Print}

\section{Tweet}

N.B.: When citing this work, cite the original article.

Original Publication:

Daniel Edström, Davide G. Sangiovanni, Lars Hultman and Valeriu Chirita, Effects of atomic ordering on the elastic properties of TiN- and VN-based ternary alloys, 2014, Thin Solid Films, (571), Part 1, 145-153.

http://dx.doi.org/10.1016/j.tsf.2014.09.048

Copyright: Elsevier

http://www.elsevier.com/

Postprint available at: Linköping University Electronic Press

http://urn.kb.se/resolve?urn=urn:nbn:se:liu:diva-111949 


\title{
Effects of atomic ordering on the elastic properties of
}

\section{TiN- and VN-based ternary alloys}

\author{
D. Edström, * D. G. Sangiovanni, L. Hultman, and V. Chirita
}

Department of Physics, Chemistry, and Biology (IFM)

Linköping University, SE-58183 Linköping, Sweden

\begin{abstract}
Improved toughness is one of the central goals in the development of wear-resistant coatings. Previous studies of toughness in transition metal nitride alloys have addressed the effects of chemical composition in these compounds. Herein, we use density functional theory to study the effects of various metal sublattice configurations, ranging from fully ordered to fully disordered, on the mechanical properties of VM2N and TiM2N (M2 = W, Mo) ternary alloys. Results show that all alloys display high incompressibility, indicating strong Me-N bonds. Disordered atomic arrangements yield lower values of bulk moduli and $\mathrm{C}_{11}$ elastic constants, as well as higher values of $\mathrm{C}_{44}$ elastic constants, compared to ordered structures. We attribute the low $\mathrm{C}_{44}$ values of ordered structures to the formation of fully-bonding states perpendicular to the applied stress. We find that the ductility of these compounds is primarily an effect of the increased valence electron concentration induced upon alloying.
\end{abstract}

Keywords: Nitrides, density functional theory, elastic properties, ductility, toughness

*Corresponding author: Daniel Edström, Tel. 0046 13286693, Fax 004613137568 , daned@ifm.liu.se 


\section{Introduction}

Transition metal nitrides are commonly employed as protective coatings in the cutting tool industry due to their excellent properties, such as high hardness and wear resistance, high melting temperature, and chemical inertness [1-3]. In particular, hard coatings prevent the surfaces of the components from being scratched and worn at extreme working pressures, thus significantly enhancing the lifetime of tools and reducing costs.

During the past two decades, development of coating materials with increasingly higher hardness has been one of the major focus areas of materials science. Great success has been achieved using a variety of experimental approaches, which generally aim to enhance hardness by reducing the mobility of dislocations. These include, for instance, synthesis of nano-scale composites [4,5] and vacancy-induced hardening [6-8]. Hardness may also be improved by tuning the material valence electron concentration (VEC). Jhi et al. [9] demonstrated that a VEC of 8.4 yields maximum hardness in cubic transition metal nitride and carbide alloys, as shear resistant metal-N/C d-p electronic states are fully occupied, while metallic d-d states remain empty. Hugosson et al. [10,11] employed VEC-tuning to set the cubic and hexagonal structures of transition metal nitride and carbide alloys to equal energy, thus promoting the formation of stacking faults, which increases hardness by hindering slip across the faults.

Hard materials are less responsive to plastic deformations. This limits their ability to dissipate stresses by plastic flow, and results in crack formation and 
propagation leading to brittle failure. Ceramics, such as transition metal nitrides, are inherently brittle [12,13], and consequently, modern hard ceramic thin film coatings are prone to brittle failure, especially during in-use conditions [14,15], for example in cutting tool applications. It is thus a priority to design coating materials which, aside from being hard, are also ductile. The combination of hardness and ductility in a material is referred to as high toughness.

In previous studies $[16,17]$, we predicted that ordered cubic $\mathrm{Ti}_{0.5} \mathrm{Mo}_{0.5} \mathrm{~N}$, $\mathrm{Ti}_{0.5} \mathrm{~W}_{0.5} \mathrm{~N}, \mathrm{~V}_{0.5} \mathrm{Mo}_{0.5} \mathrm{~N}$, and $\mathrm{V}_{0.5} \mathrm{~W}_{0.5} \mathrm{~N}$ alloys are not only harder, but also significantly more ductile than their parent binaries TiN and VN. The enhanced toughness in these ternary alloys was shown to be induced by the increased occupation of the metallic states at the Fermi level, due to the higher VEC obtained upon the substitution of Ti/V with $\mathrm{Mo} / \mathrm{W}$ atoms on the metallic $(M e)$ sublattice. The higher VEC not only preserves the typically strong $M e-\mathrm{N}$ bonds found in binaries, but enables the formation of stronger Me-Me bonds compared to TiN and VN. Overall, high VEC lowers the shear resistance and energetically promotes dislocation glide, thus leading to increased ductility.

Experimental verification of these predictions was recently provided by the synthesis and testing of cubic single-crystal $\mathrm{V}_{0.5} \mathrm{Mo}_{0.5} \mathrm{~N}_{\mathrm{x}}(0.55<\mathrm{x}<1)$ thin films $[18,19]$. Stoichiometric VMoN alloys are harder than VN [18], and the hardness of $\mathrm{VMoN}_{\mathrm{x}}$ films increases with the addition of $\mathrm{N}$ vacancies [19]. Moreover, nanoindentation experiments conducted at constant penetration show that, while VN and TiN films systematically crack, $\mathrm{V}_{0.5} \mathrm{Mo}_{0.5} \mathrm{~N}$ films never exhibit crack formation $[18,19]$. In contrast, the alloy samples display material pile-up, due to plastic flow, in the regions adjacent to the indented area, which is characteristic of ductile materials. 
The deposited VMoN films, however, show no evidence of ordering on the metal sublattice.

Single-crystal cubic-B1 $\mathrm{V}_{1-\mathrm{x}} \mathrm{W}_{\mathrm{x}} \mathrm{N}$ thin films, which is another ternary alloy we predicted to possess enhanced toughness, have also been recently synthesized in the compositional range $0<x<0.60$ [20,21]. These films exhibit a monotonic increase in hardness with $\mathrm{x}$, of up to $55 \%$, at $\mathrm{x}=0.60$, as well as reduced elastic modulus and increased Cauchy pressures $\left(\mathrm{C}_{12}-\mathrm{C}_{44}\right)$, both of which are indicative of enhanced toughness. We note that alloying TiAlN with $\mathrm{WN}$ has a similar effect on the hardness of TiAlWN thin films [22], in agreement with our predictions for TiAlN-based quaternaries [23]. Local [111] ordering has been observed in $\mathrm{V}_{0.6} \mathrm{~W}_{0.4} \mathrm{~N}$ films deposited at $600-700{ }^{\circ} \mathrm{C}$ [20], while films grown at higher temperatures showed no evidence of ordering. Long-range CuPt ordering on the metal sublattice was observed in $\operatorname{Ti}_{0.5} \mathrm{~W}_{0.5} \mathrm{~N}$ thin films grown on $\mathrm{MgO}(001)$ substrates at $500^{\circ} \mathrm{C}[24]$.

Our previous theoretical predictions of toughness enhancements in $M 1_{0.5} M 2_{0.5} \mathrm{~N}(M 1=\mathrm{Ti}, \mathrm{V} ; M 2=\mathrm{Mo}, \mathrm{W})$ alloys $[16,17]$, were based on calculations carried out on structures with long-range order, closely resembling the ideal $\mathrm{CuPt}$ arrangement observed in $\mathrm{Ti}_{0.5} \mathrm{~W}_{0.5} \mathrm{~N}$ thin films [24]. However, the experimental results show that as-deposited cubic $M 1_{0.5} M 2_{0.5} \mathrm{~N}$ films are solid solutions in most cases. To date, the effect of ordering on the metallic sublattice, on the elastic properties of these ceramics, has not been investigated. In this paper, we use density functional theory (DFT) calculations to assess the effects of varying the metal sublattice atomic arrangement, from highly ordered to fully disordered, on the formation energies and the mechanical properties of $M 1_{0.5} M 2_{0.5} \mathrm{~N}$ alloys. Our results show that while the elastic properties of these alloys vary, and thus depend on the degree of order on the cation 
sublattice, the enhanced toughness of these compounds, as demonstrated experimentally, remains primarily a VEC effect.

\section{Computational details}

We use the Vienna ab initio simulation package (VASP) [25] to perform DFT calculations in the generalized gradient approximation of Perdew-Wang (GGA-PW91) [26]. Electron-ion interactions are described using projector augmented wave potentials (PAW) [27]. Total energies are minimized to converge within $10^{-5} \mathrm{eV}$ using an energy cut-off of $500 \mathrm{eV}$ for the plane wave basis set. For each alloy, we investigate the physical properties of five different atomic arrangements, as shown in Fig. 1: ordered

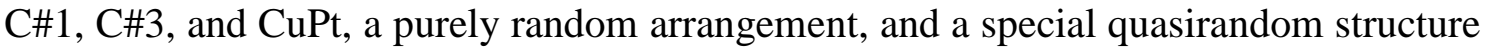
(SQS) [28]. 
(a)

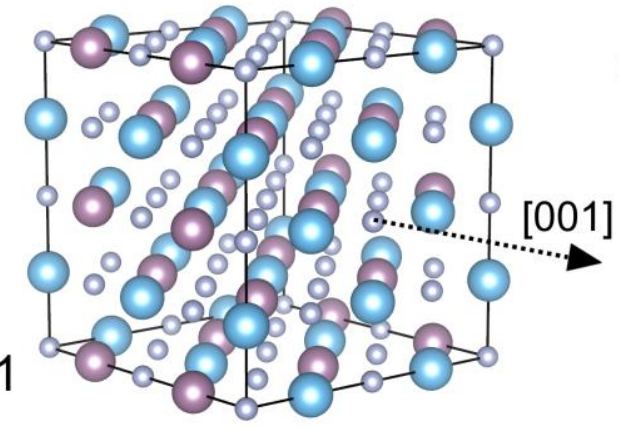

C\#1

(c)

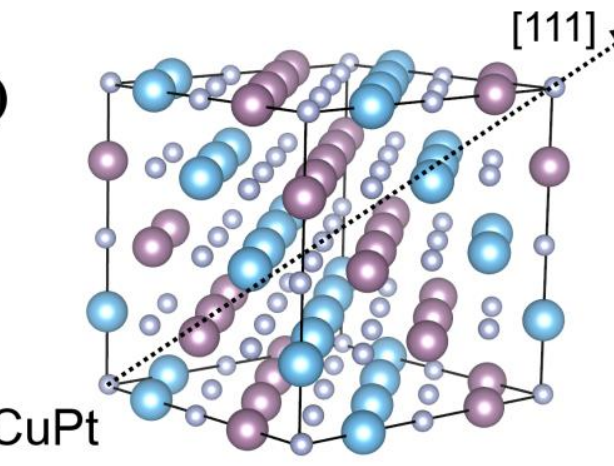

(b)

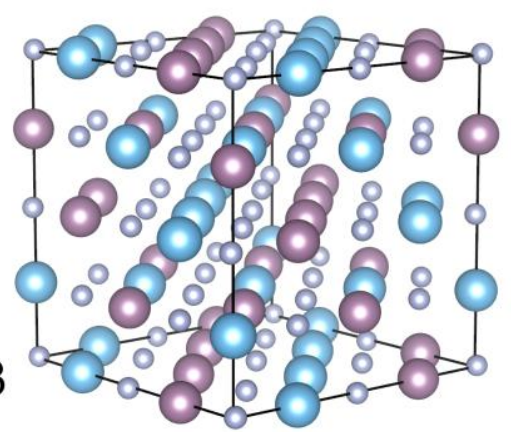

(d)

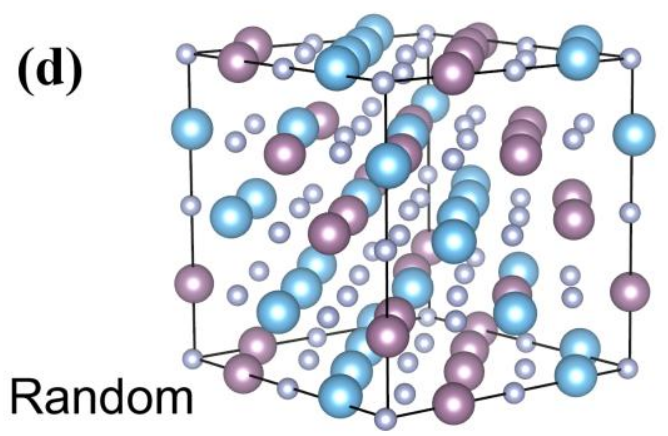

Random

\section{C\#3}

(e)

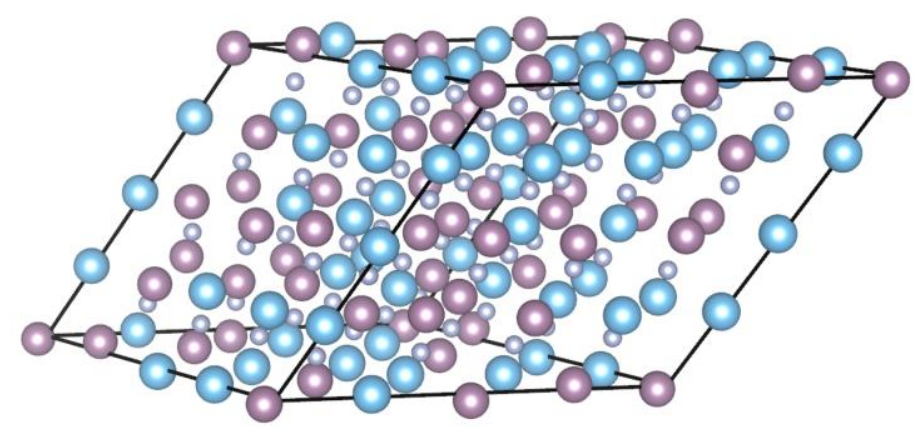

SQS 
point grids. Charge transfer maps are obtained by subtracting superimposed atomic wave function charge densities from calculated alloy charge densities. Figures of charge density maps and charge transfer maps are produced using the VESTA [30] and the STRender codes.

The $\mathrm{C} \# 1$ structure is the $\mathrm{L} 1_{0}$ variant of the rocksalt structure, as it contains alternating $M 1 / \mathrm{N}$ and $M 2 / \mathrm{N}$ (001) planes (Fig. 1a), and has tetragonal symmetry. The C\#3 structure, used in our previous studies [16,17] consists of alternating (111) planes containing $75 / 25 \%$, respectively $25 / 75 \%, M 1 / M 2$ ratios (Fig. 1b). The C\#3 structure is closely related to the CuPt arrangement (Fig. 1c), which consists of alternating (111) planes containing $100 \% M 1$ or $M 2$ atoms, respectively. We note that while the C\#3 structure has cubic symmetry, the CuPt structure, which corresponds to $\mathrm{L}_{1}$ ordering, is rhombohedral. From the CuPt structure, the C\#3 structure can be formed by rotating every other (001) plane by $90^{\circ}$. The atomic configuration shown in Fig. 1d, which mimics an intermediate level of short-range disorder in the crystal, is obtained by arbitrarily placing $M 1 / M 2$ atoms on the metallic sublattice, and is referred to herein as the Random structure. The SQS-structure supercell is formed by inter-penetrating 64fcc-sites $M e$ and $\mathrm{N}$ sublattices (Fig. 1e), and has non-orthogonal primitive vectors, in order to minimize $\mathrm{Me}-\mathrm{Me}$ correlations on neighboring shells. This procedure allows for the simulation of fully disordered solid solutions.

To assess the degree of short-range order (SRO) in our alloys we use the Warren-Cowley $\alpha$ parameter [31]. For pseudo-binaries $M 1_{1-\mathrm{x}} M 2_{\mathrm{x}} \mathrm{N}$, this is defined as $\alpha_{\mathrm{n}}$ $=1-\mathrm{P}_{M 2}\left(\mathrm{R}_{\mathrm{n}}\right) / \mathrm{x}$, where $\mathrm{P}_{M 2}\left(\mathrm{R}_{\mathrm{n}}\right)$ is the probability of finding an atom $M 2$ on the $\mathrm{n}^{\text {th }}$ neighboring shell, at a distance $\mathrm{R}$, from a $M I$ atom. Ideal solid solutions will thus have $\alpha$ values close to zero on all neighboring shells. Negative $\alpha$ values on any neighboring 
shell are indicative of ordering. This means that the probability of finding $M 1$ atoms, on spheres of radii $\mathrm{R}_{\mathrm{n}}$ centered on $M 2$ atoms, is larger than the average $M 1$ concentration on the metallic sublattice. Positive $\alpha$ values, instead, are indicative of clustering, i.e. the probability of finding $M 1$ atoms on neighboring shells centered on $M 1$ atoms is larger than the average $M 1$ concentration on the metallic sublattice. Thus, both positive and negative $\alpha$ values, with extremes +1 and -1 , are indicative of highly correlated atomic positions on neighboring spherical shells.

In figure 2 we plot the values of the Warren-Cowley $\alpha$ parameter obtained for the five structures studied herein, as calculated on neighboring spherical shells extending up to ten interatomic distances $\left(10 \times \mathrm{d}_{\mathrm{NN}} \sim 2 \mathrm{~nm}\right)$. As expected, the $\mathrm{C \# 1}, \mathrm{C \# 3}$, and $\mathrm{CuPt}$ structures are highly ordered within both short and long interatomic-distance intervals. The degree of disorder is clearly higher in the Random structure, compared to

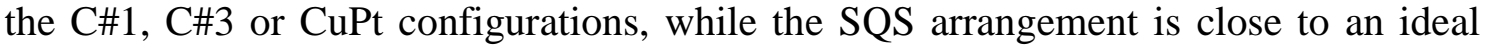
solid solution, and has the highest degree of disorder over the entire interatomicdistance range. 


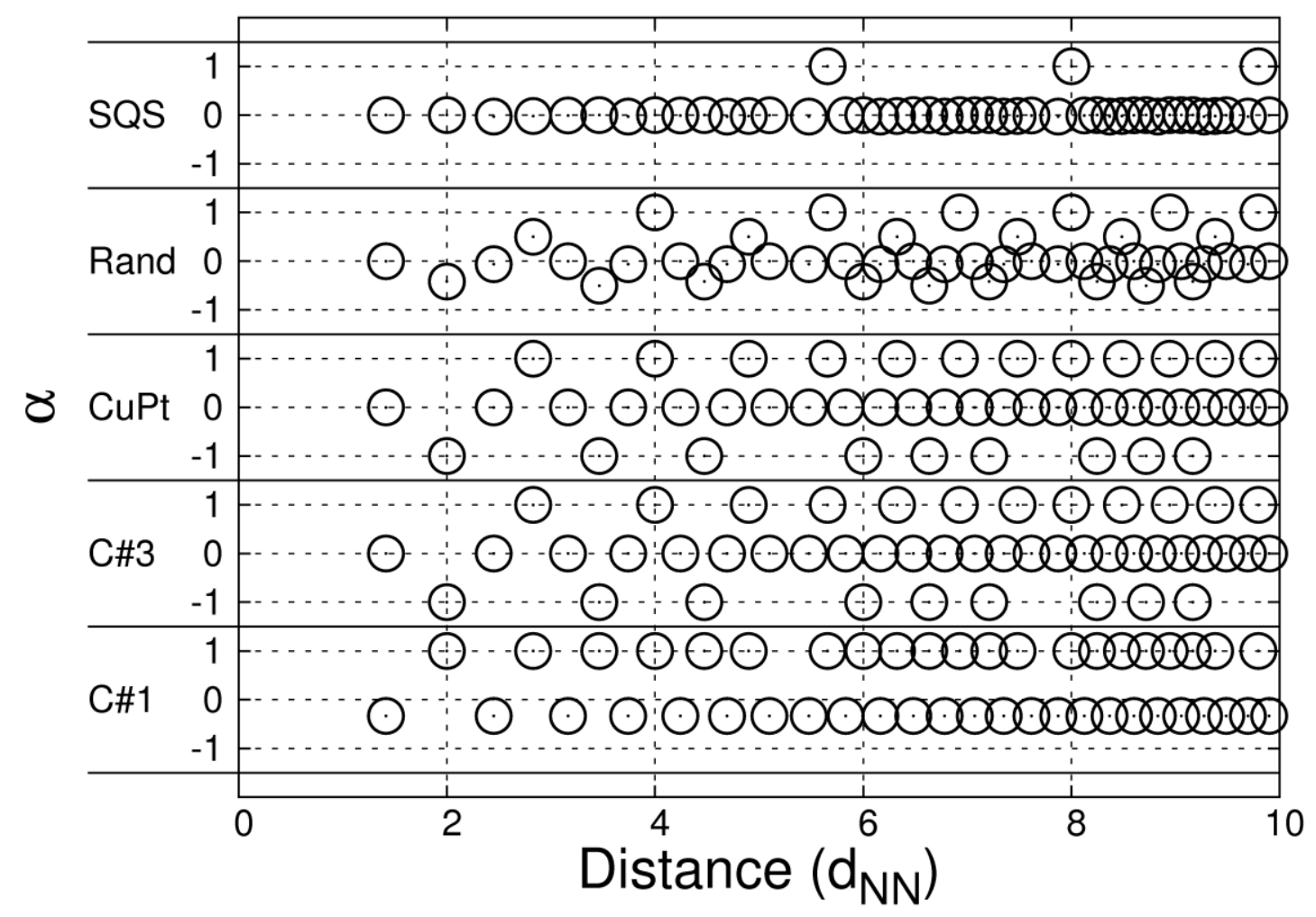

Figure 2: Warren-Cowley short range order parameters, plotted as a function of interatomic-distance, for the studied atomic configurations.

For each alloy and atomic configuration, we calculate formation energies $\Delta E$, lattice constants $a$, bulk moduli $B$, elastic constants $C_{11}, C_{12}$ and $C_{44}$, Young's and shear moduli $E$ and $G$, Poisson's ratios $v$, and anisotropy factors $A$. From total energies $E_{M 1_{0.5} M 2_{0.5} N}$ of equilibrium structures, we estimate alloy formation energies $\Delta E$ according to:

$$
\Delta E=E_{M 1_{0.5} M 2_{0.5} N}-0.5 E_{\text {cubic } M 1 N}-0.5 E_{\text {cubic/hexagonal } M 2 N} .
$$

The total energies of cubic and hexagonal (hex-WC) reference binaries $M 1 \mathrm{~N}$ and $M 2 \mathrm{~N}$ structures are calculated separately using 6x6x6 and 7x7x7 k-point grids, respectively.

Average lattice constants $a$ are obtained from $a=V^{1 / 3}$, where $V$ is the unit cell equilibrium volume. The bulk modulus is calculated by fitting the energy-volume curve 
to the Birch-Murnaghan equation of state [32]. Cubic systems exhibit three independent elastic constants, namely $C_{11}, C_{12}$ and $C_{44}$. With the exception of C\#3 lattices, the supercells used in the present study do not possess cubic point-group symmetries. However, by using a symmetry-based projection technique it is possible to find the closest elastic tensor with cubic symmetry $[33,34]$. The projected cubic elastic constants are found as averages according to

$$
\begin{aligned}
& \bar{C}_{11}=\frac{C_{11}+C_{22}+C_{33}}{3}, \\
& \bar{C}_{12}=\frac{C_{12}+C_{13}+C_{23}}{3}, \\
& \bar{C}_{44}=\frac{C_{44}+C_{55}+C_{66}}{3} .
\end{aligned}
$$

The elastic constants are calculated by fitting energy versus strain. We use a strain of $|\delta| \leq 0.005$. Anisotropy factors A are then determined from the expression

$$
A=\frac{2 \bar{C}_{44}}{\bar{C}_{11}-\bar{C}_{12}} .
$$

Elastic moduli E, G, and Poisson's ratios $v$ are determined by means of the Voigt (V), Reuss (R), and Hill (H) expressions:

$$
\begin{gathered}
G_{V}=\frac{3 \bar{C}_{44}+\bar{C}_{11}-\bar{C}_{12}}{5}, \\
G_{R}=\frac{5 \bar{C}_{44}\left(\bar{C}_{11}-\bar{C}_{12}\right)}{3\left(\bar{C}_{11}-\bar{C}_{12}\right)+4 \bar{C}_{44}}, \\
G_{H}=\frac{G_{V}+G_{R}}{2},
\end{gathered}
$$




$$
\begin{gathered}
E_{V, R, H}=\frac{9 B G_{V, R, H}}{3 B+G_{V, R, H}}, \\
v_{V, R, H}=\frac{3 B-G_{V, R, H}}{2\left(3 B+G_{V, R, H}\right)} .
\end{gathered}
$$

The use of the expressions (6)-(10) for the estimation of elastic moduli allows for direct comparison with nanoindentation measurements [35].

\section{Results and discussion}

Table 1 shows the calculated formation energies $\Delta \mathrm{E}$ for each alloy and atomic configuration, as well as corresponding calculated and experimental lattice constants. The values for energy per atom of the reference binaries are provided in Table 2. A clear trend in formation energy of cubic phases, as a function of the degree of order on the metallic sublattice, is immediately observed for all alloys. In each case, the disordered SQS arrangement, followed by the Random configuration, are the most energetically favored structures at $0 \mathrm{~K}$. Temperature will further promote disorder on the cation sublattice, due to increasingly larger contributions of the configurational entropy to the free energy. The positive $\Delta \mathrm{E}$ values obtained for $\mathrm{B} 1-M 1 \mathrm{~N} / \mathrm{h}-M 2 \mathrm{~N}$ mixing suggest that the studied alloys are metastable with respect to separation in the B1 and hexagonal phases. However, as demonstrated experimentally, these thin films can be synthesized in the B1 structure $[19,21,24,36]$.

As expected, the $\mathrm{CuPt}$ and $\mathrm{C \# 3}$ structures are found to have similar formation energies, with the CuPt slightly more stable. The difference in energy between ordered $\mathrm{CuPt}$ and disordered SQS structures, 100-130 meV/atom for VM2N and 50-60 meV/atom for TiM2N alloys, suggests that $\langle 111\rangle$ atomic ordering is less likely to be achieved in the studied VN-based compared to TiN-based alloy thin films. Crystal 
growth by sputtering, however, is a non-equilibrium process; suitable deposition parameters can promote the formation of short-range [20] or long-range [24] <111> ordered transition metal nitride layers. The $\mathrm{C \# 1}$ structure is the least stable in all cases, even displaying positive formation energies for the $\mathrm{VMoN}$ alloy. This indicates the $\mathrm{L}_{0}$ ordering of $M 1 / M 2$ atoms on the cation sublattice is energetically unfavored.

Calculated average lattice constants (Table 1) are not significantly affected by the degree of configurational order on the metallic sublattice for any of the studied alloys. The theoretical results are in good agreement with experimental measurements $[19,21,24,37,38]$. Calculated lattice parameters are approximately equal to $4.3 \AA$ for TiMoN and TiWN, and 4.25 $\AA$ for VMoN and VWN. The discrepancy, $\sim 1 \%$, is within the error of DFT+GGA, which tends to overestimate lattice parameters [39]. Due to the point group symmetry reduction, from a cubic solid solution to $\mathrm{CuPt}$, the $\mathrm{Ti}_{1-\mathrm{x}} \mathrm{W}_{\mathrm{x}} \mathrm{N}(001)$ thin film out-of-plane lattice parameter $a_{\perp}$ relaxes from 4.251 to $\sim 4.226 \AA$ for $\mathrm{W}$ concentrations $\mathrm{x}=0.5$ [24]. The measured $a_{\perp}$ relaxation translates into a corresponding decrease in the relaxed average $\mathrm{Ti}_{0.5} \mathrm{~W}_{0.5} \mathrm{~N}$ lattice parameter $a_{0}[21]$, which is obtained from the expression

$$
\Delta a_{0}=1-\frac{a_{0}^{c u b i c}}{a_{0}^{C u P t}}
$$

for which

$$
a_{0}=\frac{a_{\perp}(1-v)+2 v a_{\|}}{1+v}
$$

where $v$ is the $\operatorname{Ti}_{0.5} \mathrm{~W}_{0.5} \mathrm{~N}$ Poisson's ratio (0.384) obtained from present DFT calculations, and $a_{\|}$is the in-plane $\mathrm{Ti}_{0.5} \mathrm{~W}_{0.5} \mathrm{~N}(001)$ lattice parameter. Regardless of the magnitude of $a_{\|}$(not reported in [24]) the TiWN thin film relaxation along the [001] 
growth direction corresponds to a $a_{0}$ decrease of $\sim 0.25 \%$, in good agreement with our calculations which estimate a reduction in $a_{0}$ due to change of symmetry from cubic solid solution $\left(a_{\mathrm{SQS}}=4.307 \AA\right)$ to $\mathrm{CuPt}\left(a_{\mathrm{CuPt}}=4.299 \AA\right)$ of $\sim 0.19 \%$.

Calculated elastic properties for VWN, VMoN, TiWN, and TiMoN are found in Tables 3 to 6. Elastic properties for the parent binaries VN [17] and TiN [16] are included for reference. The indexes v, r, and h correspond to Voigt, Reuss, and Hill averages, respectively. As can be seen from Table 3, alloying VN with WN has little effect on the bulk modulus as compared to the parent VN binary. A small increase in B can be seen for the ordered alloys, of the order of $10 \%$. In the fully-disordered SQS and Random alloys, instead, there is a $2 \%$ decrease of B. For all structures, however, W substitutions induce significant Young's and shear moduli reductions; $31 \%-40 \%$ for $E_{h}$, and $35 \%-45 \%$ for $G_{h}$. Similar effects are seen in the VMoN alloys (Table 4) for all calculated elastic moduli. In this case, B increases for the highly ordered structures by $4 \%$, and decreases by $6-7 \%$ for the fully-disordered SQS and Random structures. Likewise, $\mathrm{E}_{\mathrm{h}}$ and $\mathrm{G}_{\mathrm{h}}$ for $\mathrm{VMoN}$ decrease by $30-55 \%$ compared to VN values. We note that there is no clear dependence between the decreases observed in either E or G, and the degree of disorder in either alloy. For example, the VMoN structure with smallest $\mathrm{E}_{\mathrm{h}}$ is the $\mathrm{CuPt}$, while for $\mathrm{VWN}$ it is the $\mathrm{C \# 1}$.

The significant trend, however, is that regardless of the atomic arrangement on the metallic sublattice, alloying VN with $\mathrm{WN}$ or MoN significantly reduces the $\overline{\mathrm{C}}_{44}$ elastic constant-in each case. The $\overline{\mathrm{C}}_{44}$ values of ordered configurations for VWN alloys decrease by as much as $56 \%$, and those of VMoN alloys by $69 \%$, compared to the $\overline{\mathrm{C}}_{44}$ value of pure VN. For the Random and the SQS structures, the $\overline{\mathrm{C}}_{44}$ reductions are smaller, but nevertheless still considerable, $32 \%$ and 35\%, for VWN and VMoN alloys, 
respectively. A similar, general decrease, though not of the same magnitude, can be observed for the $\overline{\mathrm{C}}_{11}$ elastic constant values, indicating lower resistance to tensile $<100>$-deformation, in both VWN and VMoN ternaries. In this case, however, the largest $\overline{\mathrm{C}}_{11}$ reduction is obtained for disordered structures. In summary, all VN-based alloys studied herein, regardless of the degree of order on the metal sublattice, exhibit small changes in $\mathrm{B}$, and significantly lower $\mathrm{E}, \mathrm{G}, \overline{\mathrm{C}}_{44}$, and $\overline{\mathrm{C}}_{11}$ values, compared to the parent VN binary. The largest reductions in $\overline{\mathrm{C}}_{44}$ values are obtained for ordered structures, respectively in disordered configurations for $\overline{\mathrm{C}}_{11}$ values. Overall, these results indicate that replacing $\mathrm{V}$ with $\mathrm{W}$ or $\mathrm{Mo}$ atoms on the $\mathrm{VN}$ metal sublattice reduces both the shear $\left(\overline{\mathrm{C}}_{44}\right.$ and $\left.\mathrm{G}\right)$ and tensile $\left(\overline{\mathrm{C}}_{11}\right)$ resistance to deformation, while preserving high incompressibility $(\mathrm{B}>\sim 300 \mathrm{GPa})$.

For TiN-based ternaries, results show that upon alloying TiN with either WN or MoN, and regardless of the degree of order on the metal sublattice, the formed alloys possess increased bulk moduli, primarily for ordered structures (Table 5 and Table 6). At the same time, as observed for VN-based ternaries, $E_{h}$ and $G_{h}$ are reduced, for both TiWN and TiMoN alloys, by up to $33 \%$. In this case, however, the largest reductions are observed in disordered configurations. Furthermore, regardless of the degree of order on the metallic sublattice, the $\overline{\mathrm{C}}_{44}$ elastic constant is reduced, as compared to the parent binary TiN, in both TiWN and TiMoN alloys. The $\overline{\mathrm{C}}_{44}$ values of TiWN alloys decrease by up to $52 \%$ (Table 5), while those of TiMoN alloys by up to $43 \%$ (Table 6), and in both cases, the largest reductions in $\overline{\mathrm{C}}_{44}$ are observed for ordered structures. In terms of $\overline{\mathrm{C}}_{11}$ elastic constant values, the trend in TiN-based alloys is somewhat different to that observed in VN-based alloys, in the sense that for both TiWN and TiMoN alloys, we obtain marginally higher $\overline{\mathrm{C}}_{11}$ values for ordered structures, and lower $\overline{\mathrm{C}}_{11}$ values in 
disordered configurations, compared to the $\overline{\mathrm{C}}_{11}$ value of the TiN parent binary. Overall, the elastic properties dependence on the degree of order, is similar for both $\mathrm{VN}$ - and TiN-based alloys, as the lowest $\overline{\mathrm{C}}_{44}$ and $\overline{\mathrm{C}}_{11}$ values are found for ordered, and disordered structures, respectively.

With respect to comparing our calculations to experiments, we note that the elastic constants of $\mathrm{VN}$ - and TiN-based alloys have not been yet measured experimentally. However, our calculated Young's moduli E values are consistent with the results of indentation measurements conducted on samples with chemical compositions similar to those used in the present study. This can be seen in Table 7, in which the Young moduli values predicted with DFT, and the corresponding experimental values $[19,21,36,40]$, are presented. It should be noted that due to effects of anisotropy during nanoindentation, the experimental Young's moduli do not directly correspond to the calculated Young moduli. Nevertheless, there is qualitative agreement between the experimental and calculated values.

Naturally, the changes in bulk moduli and elastic constants reported above reflect upon a number of other alloy properties, such as the G/B and Poisson ratios, and the Cauchy pressure, which are typically used to estimate the trend of ductility in materials [41]. According to the Pugh [42] and Pettifor [43] criteria, which reflect the phenomenological relationship between the elastic constants and the covalent/metallic character in chemical bonds, ductility is associated with $\mathrm{G} / \mathrm{B}<0.5$ and positive Cauchy pressures $\left(\mathrm{C}_{12}-\mathrm{C}_{44}\right)$. Based on these criteria, our results clearly show that both $\mathrm{VN}$ - and TiN-based alloys, regardless of the degree of order on the metallic sublattice, are significantly more ductile than the parent $\mathrm{VN}$ and TiN binaries. For VN-based alloys (Table 3 and Table 4), Cauchy pressures lie in the interval [108, 165] GPa, significantly 
above the $\mathrm{VN}$ value $(1 \mathrm{GPa})$, and the $\mathrm{G}_{\mathrm{h}} / \mathrm{B}$ ratios, within the interval $[0.245,0.377]$, are drastically smaller than the value of 0.569 of the parent binary. Likewise, compared with TiN, which has a Cauchy pressure of $-44 \mathrm{GPa}$ and $\mathrm{G}_{\mathrm{h}} / \mathrm{B}$ ratio of 0.671 , we find TiN-based alloys to have positive Cauchy pressures, in the [61, 110] GPa interval, and $\mathrm{G}_{\mathrm{h}} / \mathrm{B}$ ratios between 0.384 and 0.448 .

The ductility trends for VN- and TiN-based alloys are illustrated in the maps shown in Figs. 3a, 3b, and 3c. The corresponding values of the parent $\mathrm{VN}$ and TiN binaries are also included in the panels for comparison. As can be seen in Fig. 3a, TiNbased alloys exhibit higher $\mathrm{G}_{\mathrm{h}} / \mathrm{B}$ ratios and lower Cauchy pressures, up to $110 \mathrm{GPa}$, compared to the VN-based alloys, here predicted to be the most ductile. This observation is consistent with the findings of our previous theoretical investigations $[16,17]$, confined to the analysis of mechanical and electronic properties for alloys with highly-ordered metallic sublattices. At the same time, from Figs. $3 b$ and $3 c$, it is evident that for each ternary alloy, the Cauchy pressure and G/B data set span a wide interval on the ductility maps. This is clearly a lattice configuration effect. 
(a)

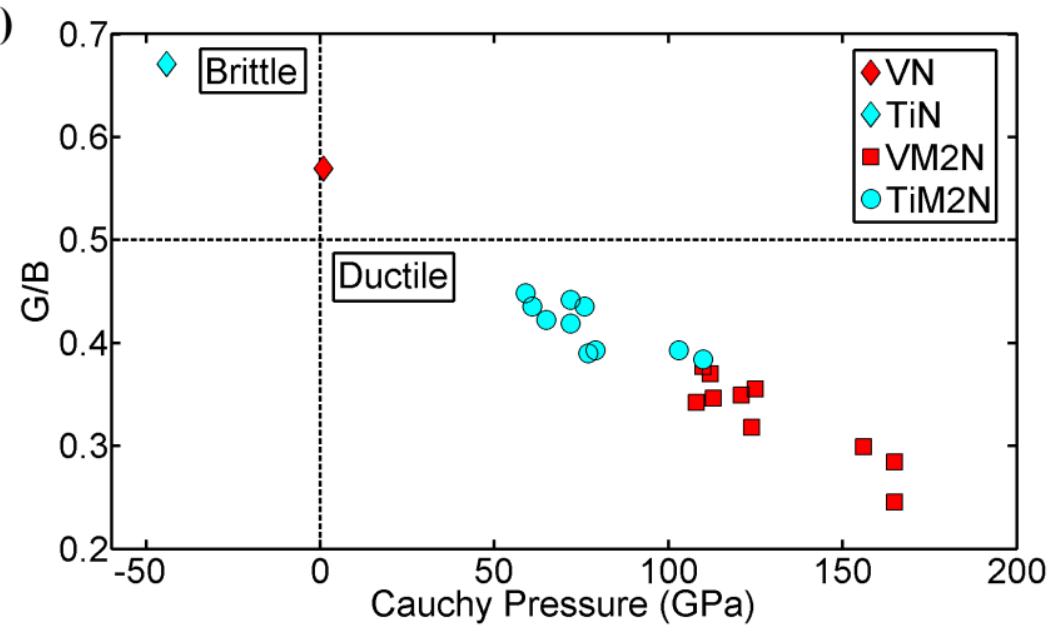

(b)

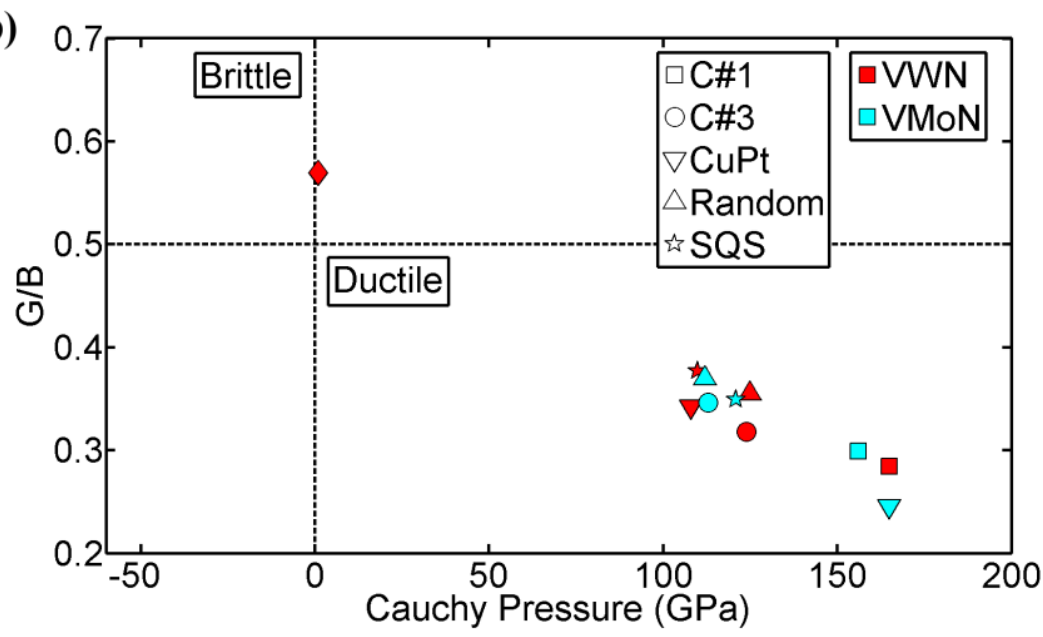

(c)

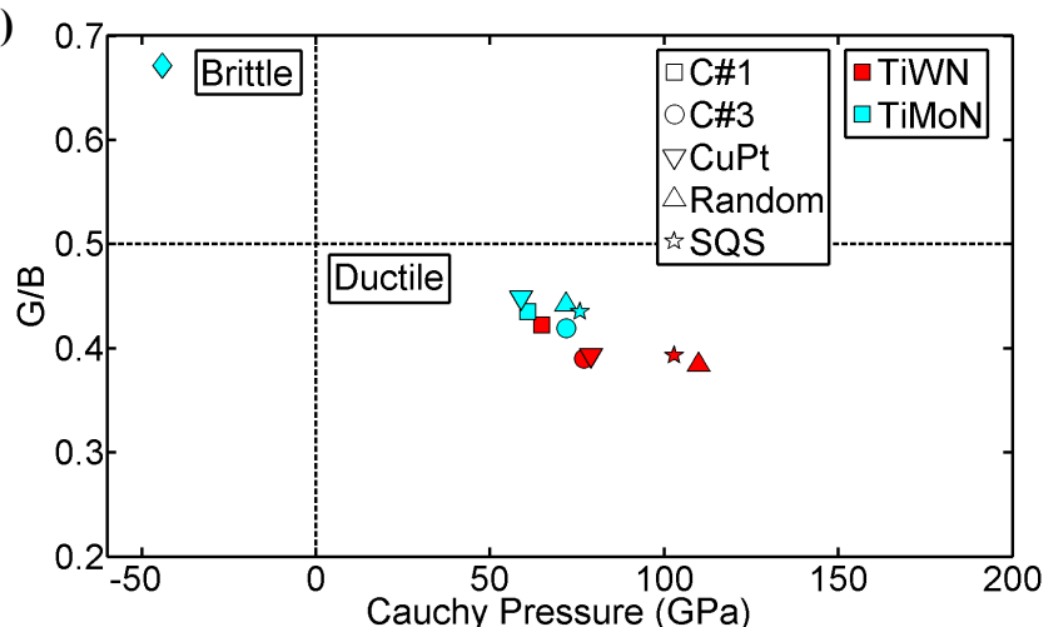

Figure 3: (a) Ductility map of $\mathrm{VN}$ - and TiN-based alloys. Reference binaries are included for comparison. (b) Ductility trends in VMoN and VWN alloys. (c) Ductility trends in TiMoN and TiWN alloys. Red symbols indicate $M 2=\mathrm{W}$, cyan symbols indicate $M 2=$ Mo. The shapes of the symbols indicate the different arrangements on the metallic sublattice. 
The VN-based and TiN-based ductility trends are shown in Fig. $3 b$ and Fig. 3c, respectively. As can be seen, the different atomic arrangements yield significant differences in the elastic properties of each ternary compound. However, no clear trend of ductility vs. order on the metallic sublattice is observable for the studied ternaries. For example, for VN-based alloys, the highly ordered structures, $\mathrm{C \# 1}$ and $\mathrm{CuPt}$, are the most ductile, while for the TiN-based alloys, the highest ductility is obtained for the fully-disordered (SQS) and the intermediately-disordered (Random) configurations. It is also clear that the VM2N alloys and the TiM2N alloys occupy distinct regions on the ductility map, with the VN-based alloys predicted to be the most ductile. Yet, it is important to note that the least ductile configurations for VM2N alloys, and the most ductile configurations for TiM2N alloys, overlap on the ductility map, a clear effect of the degree of configurational order/disorder (see also Fig. 3a). The fact that all alloy configurations, with such diverse atomic arrangements on the metallic sublattice, span only the ductile region of the map, demonstrates that although ordering affects the mechanical properties of $\mathrm{Ti} M 2 \mathrm{~N}$ and $\mathrm{V} M 2 \mathrm{~N}$ alloys, leading even to the overlap in ductility trends mentioned above, compared to the parent binaries, their enhanced ductility, and toughness, is primarily a VEC effect.

To further investigate the effect of ordering on the metallic sublattice on the mechanical properties of these alloys, we carry out a thorough electronic structure analysis. We choose for this purpose $\mathrm{V}_{0.5} \mathrm{Mo}_{0.5} \mathrm{~N}$ alloys, in all ordering configurations considered herein, as for these films, recently synthesized, the toughness enhancements were confirmed in severe nanoindentation tests $[18,19]$. The description of the electronic structure, reported below for VMoN alloys, applies to all presently studied ternaries. 
In Fig. 4, we plot the (001)-plane charge-density maps, including contour lines, of unstrained $\mathrm{V}_{0.5} \mathrm{Mo}_{0.5} \mathrm{~N}$ crystal lattices. For the $\mathrm{C} \# 1$ configuration (Fig. 4a), the electron density cut is on the (001) plane containing only Mo atoms. As can be seen in all panels (Figs. 5a-5e), V and Mo atoms are easily distinguished by the shape of the electron distribution in their vicinity; the concentric contour lines show that the electrons are localized on $\mathrm{V}$ atoms, whereas the charge around Mo atoms is more delocalized. The charge distributions in all ordered configurations, C\#1 (Fig. 4a), C\#3 (Fig. 4b), and CuPt (Fig. 4c) are very similar, as ionic-covalent bonds are formed exclusively between $\mathrm{Me}$ and $\mathrm{N}$ atoms. For the intermediately-ordered Random structure (Fig. 4d), one can observe a more irregular charge distribution and, consequently, the formation of randomly distributed $M e-M e$ bonds. Similarly, for the SQS configuration (Fig. 4e), the fully disordered atomic arrangement results in more $M e-M e$ bonds being formed between $M e$ pairs along the [110] direction. 

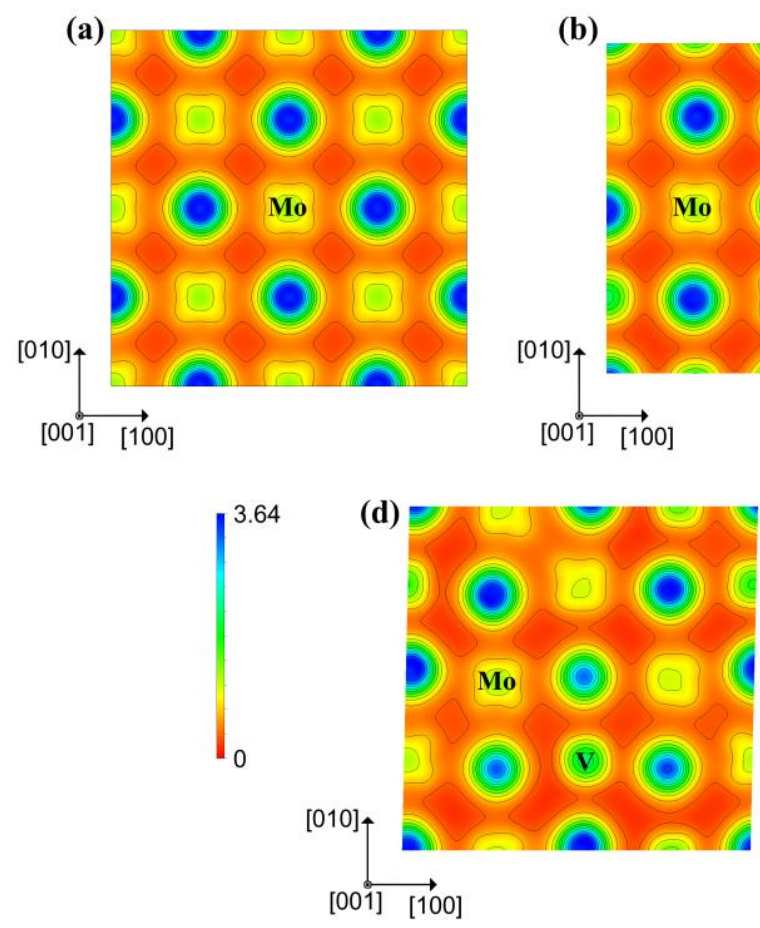

(b)

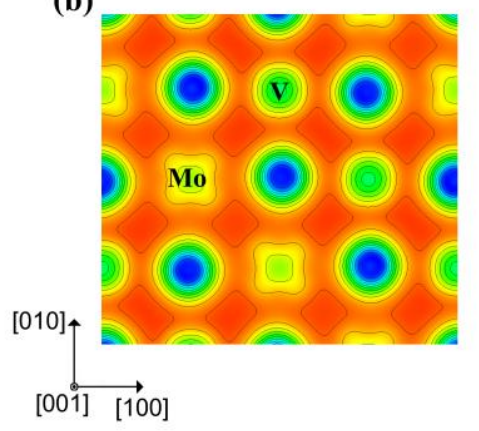

(c)

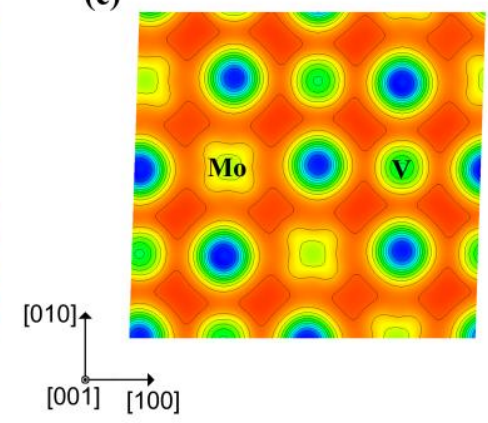

Figure 4: Charge densities of unstrained VMoN alloys with the following structures: (a) C\#1, (b) C\#3, (c) CuPt, (d) Random, (e) SQS. The cut for C\#1 is along the (001) plane containing only Mo metal atoms. The cuts for the C\#3, CuPt, Random and SQS structures are along (001) planes. The color scale is expressed in electrons $/ \AA^{3}$.

To complete the analysis, one needs to examine the chemical bond response to applied stresses. Fig. 5 illustrates the charge-density maps obtained for VMoN sheared structures; a trigonal strain of $10 \%$ is applied along the [111] direction. The five panels (Figs. 5a-5e) depict the charge distributions on the same cuts used for the unstrained configurations. As can be seen, upon shearing the C\#1 structure (Fig. 5a), secondnearest neighbor Mo-Mo bonds are formed along the strain orthogonal direction. As expected, in the C\#3 (Fig. 5b) and the CuPt (Fig. 5c) arrangements, one can observe the formation of layered electronic structures, consisting of alternating high/low charge density regions, along the [1 $1 \overline{1} 0]$-oriented Mo and $\mathrm{V}$ atomic rows, as previously shown $[16,17]$. 
(a)

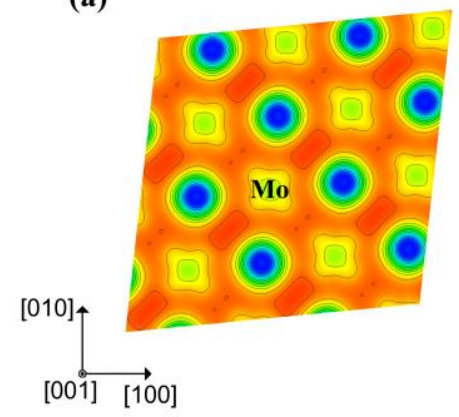

(b)

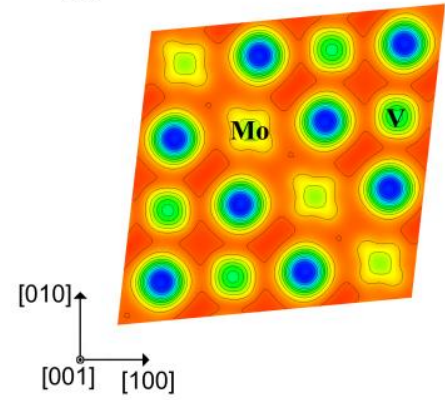

(c)

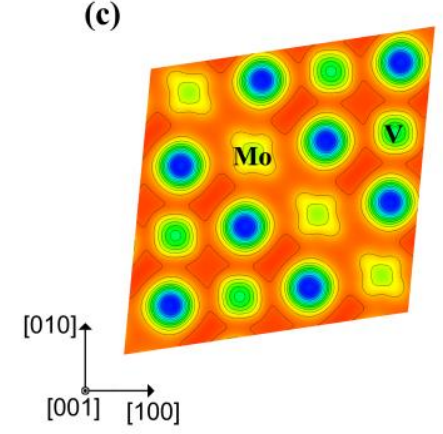

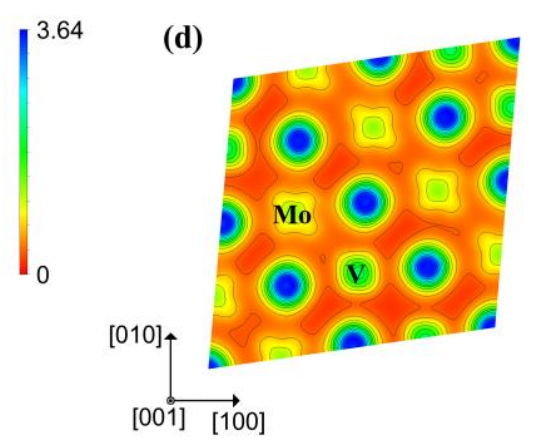

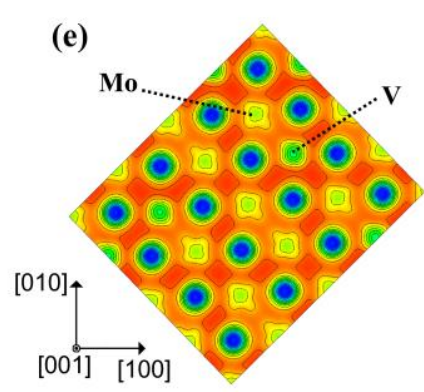

Figure 5: Charge densities of strained VMoN alloys (10\% trigonal strain), with the following structures: (a) C\#1, (b) C\#3, (c) CuPt, (d) Random, (e) SQS. The cut for C\#1 is along the (001) plane containing only Mo metal atoms. The cuts for the C\#3, CuPt, Random and SQS structures are along (001) planes. The color scale is expressed in electrons/ $\AA^{3}$.

Charge layers are also visible in the in the density map of the sheared Random structure (Fig. 5d). Clearly, the formation of $<110\rangle$-layered electron distributions upon shearing is a lattice ordering effect. Due to the trigonal deformation, for atomic rows comprised exclusively of Mo atoms, the shortening of Mo - Mo interatomic distances results in a marked electron delocalization. This indicates the formation of strong $d-d$ metallic bonds. In contrast, the electron charge remains localized onto their nuclei for closely interacting $\mathrm{V}$ atoms. In the case in which $\mathrm{V}$ and Mo atoms are nearest neighbors, shearing results in charge accumulation between the nuclei, indicating strong $\mathrm{V}-\mathrm{Mo}$ bonds. In the sheared SQS structure (Fig. 5e) one can still observe the electron-rich areas between $\mathrm{Me}-\mathrm{Me}$ atoms, as for the unstrained configuration (Fig. 4e). Due to 
shearing, however, the $M e-M e$ bonding pairs are formed along the [1̄ㅣ] direction, i.e perpendicular to the applied stress. This is the same direction along which the high/low charge layers, formed upon shearing, are aligned in the ordered structures (see Figs. 5a $-5 c)$. Generally, for the disordered SQS configuration, cuts along different planes will yield, as expected, different electron distributions. We observe the formation of pairs of Me-Me bonds along the [1ํㅣ] direction in most (001) charge-density maps.

The formation of metallic bonds upon shearing is best illustrated in Fig. 6, which shows the charge-transfer maps of VMoN alloys with the CuPt (Fig. 6a) and SQS (Fig. 6b) arrangements under 10\% [111] trigonal strain. As can be seen, in the highly ordered $\mathrm{CuPt}$ configuration, shearing induces a systematic accumulation of electrons between Mo-Mo atoms along the [1ㅣㅣ direction, i.e. the formation of fully-bonding electronic states, which stems from a chain of constructively interfering Mo 5d-waves. 
(a)

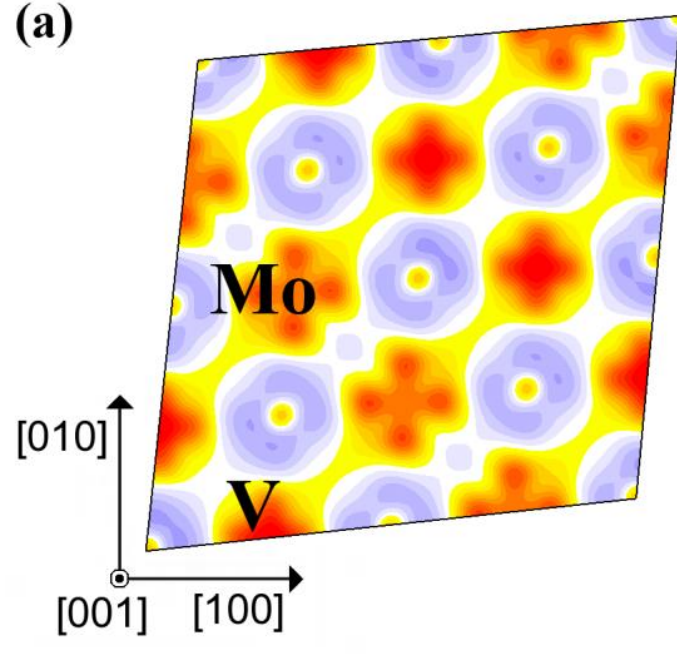

(c)

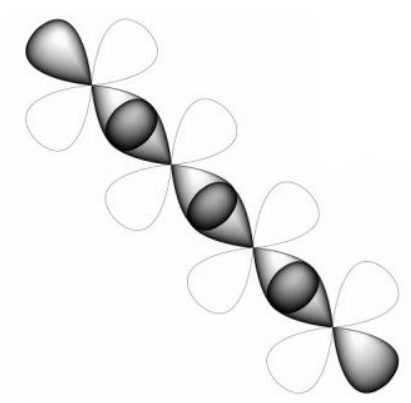

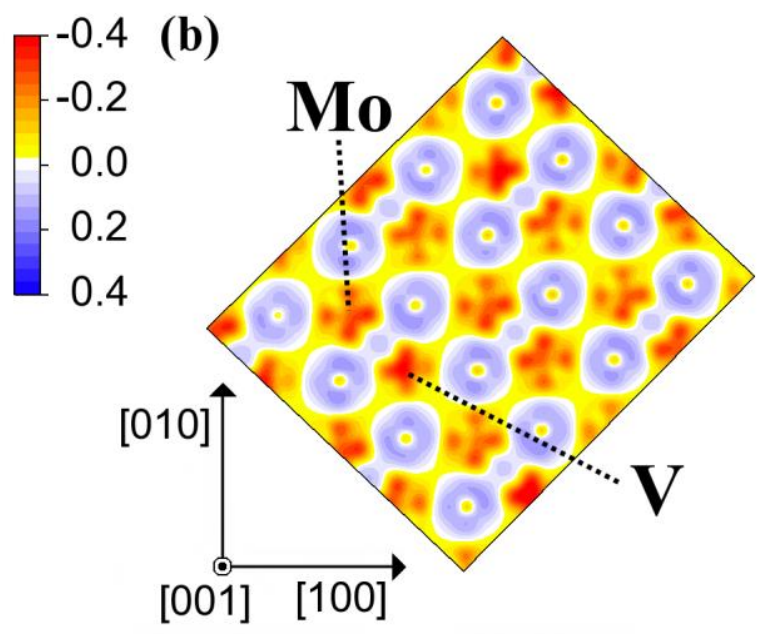

(d)

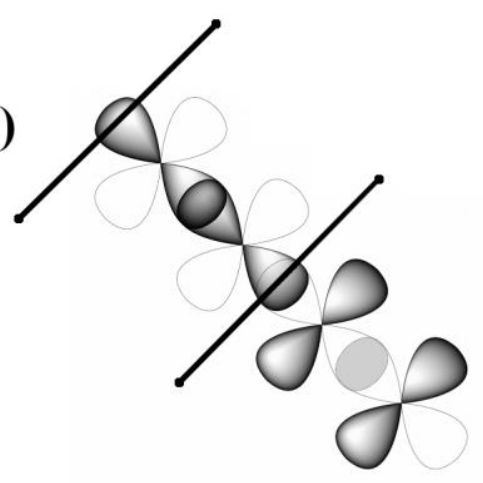

Figure 6: Charge transfer maps of sheared VMoN alloys: (a) ordered CuPt; (b) fully-disordered SQS. Corresponding overlap of d-orbitals is shown in (c) for CuPt and (d) for SQS. The color scale is expressed in electrons $/ \AA^{3}$.

The chain of d-orbitals overlapping in phase, Fig. $6 c$, schematically represents such a fully-bonding electronic state. In the sheared disordered SQS configuration (Fig. $6 b)$, the formation of metallic bonds in the strain orthogonal direction occurs only between every second $M e-M e$ pair. This phenomenon can be illustrated by a sequence of alternated in-phase/out-of-phase d orbitals (Fig. 6d), which give rise to electronaccumulation/electron-depletion centers located between Me atoms; this is a partially bonding metallic state. As demonstrated experimentally for disordered VMoN solid solutions [18], the alloy ability to form partially-bonding d-states upon mechanical 
deformation is sufficient to enhance ductility and toughness. This fact is reflected in significantly reduced shear resistance, as well as preserved strong interatomic bonds (see high bulk moduli, Tables 3-6). Summarizing, alloys with disordered structures are compliant to shearing due to an electronic mechanism which is similar to that found for ordered structures, i.e. ability to dissipate high mechanical stresses by forming metallic bonds. Ordering on the metal sublattice produces the highest tensile resistances as well as the lowest shear resistances. The enhanced toughness of $\mathrm{VN}$ - and TiN-based ternaries, however, primarily stems from the increased VEC induced by alloying.

\section{Conclusions}

We calculate the elastic properties of $\mathrm{V}_{0.5} \mathrm{~W}_{0.5} \mathrm{~N}, \mathrm{~V}_{0.5} \mathrm{Mo}_{0.5} \mathrm{~N}, \mathrm{Ti}_{0.5} \mathrm{~W}_{0.5} \mathrm{~N}$, and $\mathrm{Ti}_{0.5} \mathrm{Mo}_{0.5} \mathrm{~N}$ alloys with various degrees of order/disorder on the metallic sublattice. Results show that regardless of the atomic arrangement, all alloys exhibit high incompressibility (B > 300 GPa), indicating the presence of strong $M e-\mathrm{N}$ bonds, comparable to those of $\mathrm{TiN}$ and $\mathrm{VN}$ parent binaries. The fully-disordered and intermediately-ordered structures consistently exhibit lower values of bulk modulus and $\overline{\mathrm{C}}_{11}$, as well as higher values of $\overline{\mathrm{C}}_{44}$ compared to ordered structures. The small $(<100$ GPa) $\overline{\mathrm{C}}_{44}$ values obtained for the highly-ordered alloys are attributed to the formation, upon the application of trigonal stresses, of fully-bonding metallic states perpendicular to the direction of the applied stress. Even though reduced, a similar effect is observed in disordered structures, as evidenced by the formation of alternating pairs of strong $M e$ Me bonds upon shearing, which explains their increased compliance to this type of stresses, compared to the reference binaries. The ductility of the VN- and TiN-based alloys studied herein, while clearly affected by the degree of disorder on their metallic sublattice, is shown to be superior to that of reference binaries. Present calculations 
demonstrate that the experimentally verified toughness enhancements in these alloys are primarily an effect of increased VEC, induced upon alloying.

\section{Acknowledgements}

We appreciate financial support from the Swedish Research Council (VR) Linköping Linnaeus Initiative LiLi-NFM (Grant \# 2008-6572) and the Swedish Government Strategic Research Area Grant in Materials Science on Advanced Functional Materials. Calculations were performed using the resources provided by the Swedish National Infrastructure for Computing (SNIC), on the Neolith, Kappa, and Triolith Clusters located at the National Supercomputer Centre (NSC) in Linköping, and on the Abisko cluster located at the High Performance Computing Center North (HPC2N) in Umeå. 


\section{References}

[1] L.E. Toth, Transition metal carbides and nitrides, Academic Press, 1971.

[2] B.M. Howe, E. Sammann, J.G. Wen, T. Spila, J.E. Greene, L. Hultman, et al., Real-time control of AlN incorporation in epitaxial $\mathrm{Hf}_{1-x} \mathrm{Al}_{\mathrm{x}} \mathrm{N}$ using high-flux, low-energy $(10-40 \mathrm{eV})$ ion bombardment during reactive magnetron sputter deposition from a $\mathrm{Hf}_{0.7} \mathrm{Al}_{0.3}$ alloy target, Acta Mater. 59 (2011) 421-428.

[3] P.H. Mayrhofer, F.D. Fischer, H.J. Böhm, C. Mitterer, J.M. Schneider, Energetic balance and kinetics for the decomposition of supersaturated $\mathrm{Ti}_{1-\mathrm{x}} \mathrm{Al}_{\mathrm{x}} \mathrm{N}$, Acta Mater. 55 (2007) 1441-1446.

[4] S. Veprek, M.G.J. Veprek-Heijman, P. Karvankova, J. Prochazka, Different approaches to superhard coatings and nanocomposites, Thin Solid Films. 476 (2005) 1-29.

[5] L. Hultman, J. Bareño, A. Flink, H. Söderberg, K. Larsson, V. Petrova, et al., Interface structure in superhard TiN-SiN nanolaminates and nanocomposites: Film growth experiments and ab initio calculations, Phys. Rev. B. 75 (2007) 155437.

[6] C.-S. Shin, D. Gall, N. Hellgren, J. Patscheider, I. Petrov, J.E. Greene, Vacancy hardening in single-crystal TiN ${ }_{x}(001)$ layers, J. Appl. Phys. 93 (2003) 6025-6028.

[7] S.-H. Jhi, S.G. Louie, M.L. Cohen, J. Ihm, Vacancy Hardening and Softening in Transition Metal Carbides and Nitrides, Phys. Rev. Lett. 86 (2001) 3348-3351.

[8] C.-S. Shin, S. Rudenja, D. Gall, N. Hellgren, T.-Y. Lee, I. Petrov, et al., Growth, surface morphology, and electrical resistivity of fully strained substoichiometric epitaxial $\operatorname{TiN}_{x}(0.67 \leqslant x<1.0)$ layers on $\mathrm{MgO}(001)$, J. Appl. Phys. 95 (2003) 356362.

[9] S.-H. Jhi, J. Ihm, S.G. Louie, M.L. Cohen, Electronic mechanism of hardness enhancement in transition-metal carbonitrides, Nature. 399 (1999) 132-134.

[10] H.W. Hugosson, U. Jansson, B. Johansson, O. Eriksson, Restricting Dislocation Movement in Transition Metal Carbides by Phase Stability Tuning, Science. 293 (2001) 2434-2437.

[11] T. Joelsson, L. Hultman, H.W. Hugosson, J.M. Molina-Aldareguia, Phase stability tuning in the $\mathrm{Nb}_{\mathrm{x}} \mathrm{Zr}_{1-\mathrm{x}} \mathrm{N}$ thin-film system for large stacking fault density and enhanced mechanical strength, Appl. Phys. Lett. 86 (2005) 131922.

[12] W.K. Tredway, MATERIALS SCIENCE:Toughened Ceramics, Science. 282 (1998) 1275-1275. 
[13] W.J. Clegg, MATERIALS SCIENCE:Enhanced: Controlling Cracks in Ceramics, Science. 286 (1999) 1097-1099.

[14] A.H. Sherry, T.J. Marrow, 1.04 - Mechanical Properties and Fracture of Materials, in: B. Cottis, M. Graham, R. Lindsay, S. Lyon, T. Richardson, D. Scantlebury, et al. (Eds.), Shreirs Corros., Elsevier, Oxford, 2010: pp. 77-88.

[15] D.P.H. Hasselman, Unified Theory of Thermal Shock Fracture Initiation and Crack Propagation in Brittle Ceramics, J. Am. Ceram. Soc. 52 (1969) 600-604.

[16] D.G. Sangiovanni, V. Chirita, L. Hultman, Electronic mechanism for toughness enhancement in $\mathrm{Ti}_{\mathrm{x}} \mathrm{M}_{1-\mathrm{x}} \mathrm{N}$ (M=Mo and W), Phys. Rev. B. 81 (2010) 104107.

[17] D.G. Sangiovanni, L. Hultman, V. Chirita, Supertoughening in B1 transition metal nitride alloys by increased valence electron concentration, Acta Mater. 59 (2011) 2121-2134.

[18] H. Kindlund, D.G. Sangiovanni, L. Martínez-de-Olcoz, J. Lu, J. Jensen, J. Birch, et al., Toughness enhancement in hard ceramic thin films by alloy design, APL Mater. 1 (2013) 042104.

[19] H. Kindlund, D.G. Sangiovanni, J. Lu, J. Jensen, V. Chirita, J. Birch, et al., Vacancy-induced toughening in hard single-crystal $\mathrm{V}_{0.5} \mathrm{Mo}_{0.5} \mathrm{~N}_{\mathrm{x}} / \mathrm{MgO}\left(\begin{array}{lll}0 & 0 & 1\end{array}\right)$ thin films, Acta Mater. 77 (2014) 394-400.

[20] H. Kindlund, J. Lu, J. Jensen, I. Petrov, J.E. Greene, L. Hultman, Epitaxial V ${ }_{0.6} \mathrm{~W}$ $0.4 \mathrm{~N} / \mathrm{MgO}(001)$ : Evidence for ordering on the cation sublattice, J. Vac. Sci. Technol. Vac. Surf. Films. 31 (2013) 040602.

[21] H. Kindlund, D.G. Sangiovanni, J. Lu, J. Jensen, V. Chirita, I. Petrov, et al., Effect of WN content on toughness enhancement in $\mathrm{V}_{1-\mathrm{x}} \mathrm{W}_{\mathrm{x}} \mathrm{N} / \mathrm{MgO}(001)$ thin films, $\mathrm{J}$. Vac. Sci. Technol. Vac. Surf. Films. 32 (2014) 030603.

[22] T. Reeswinkel, D.G. Sangiovanni, V. Chirita, L. Hultman, J.M. Schneider, Structure and mechanical properties of TiAlN-WN $\mathrm{W}_{\mathrm{x}}$ thin films, Surf. Coat. Technol. 205 (2011) 4821-4827.

[23] D.G. Sangiovanni, V. Chirita, L. Hultman, Toughness enhancement in TiAlNbased quarternary alloys, Thin Solid Films. 520 (2012) 4080-4088.

[24] F. Tian, J. D’Arcy-Gall, T.-Y. Lee, M. Sardela, D. Gall, I. Petrov, et al., Epitaxial $\mathrm{Ti}_{1-\mathrm{x}} \mathrm{W}_{\mathrm{x}} \mathrm{N}$ alloys grown on $\mathrm{MgO}(001)$ by ultrahigh vacuum reactive magnetron sputtering: Electronic properties and long-range cation ordering, J. Vac. Sci. Technol. Vac. Surf. Films. 21 (2003) 140-146. 
[25] G. Kresse, J. Hafner, Ab initio molecular dynamics for liquid metals, Phys. Rev. B. 47 (1993) 558-561.

[26] J.P. Perdew, Y. Wang, Accurate and simple analytic representation of the electron-gas correlation energy, Phys. Rev. B. 45 (1992) 13244-13249.

[27] P.E. Blöchl, Projector augmented-wave method, Phys. Rev. B. 50 (1994) 1795317979.

[28] A. Zunger, S.-H. Wei, L.G. Ferreira, J.E. Bernard, Special quasirandom structures, Phys. Rev. Lett. 65 (1990) 353-356.

[29] H.J. Monkhorst, J.D. Pack, Special points for Brillouin-zone integrations, Phys. Rev. B. 13 (1976) 5188-5192.

[30] K. Momma, F. Izumi, VESTA 3 for three-dimensional visualization of crystal, volumetric and morphology data, J. Appl. Crystallogr. 44 (2011) 1272-1276.

[31] J.M. Cowley, An Approximate Theory of Order in Alloys, Phys. Rev. 77 (1950) 669-675.

[32] F. Birch, Finite strain isotherm and velocities for single-crystal and polycrystalline $\mathrm{NaCl}$ at high pressures and $300^{\circ} \mathrm{K}$, J. Geophys. Res. Solid Earth. 83 (1978) 12571268.

[33] M. Moakher, A.N. Norris, The Closest Elastic Tensor of Arbitrary Symmetry to an Elasticity Tensor of Lower Symmetry, J. Elast. 85 (2006) 215-263.

[34] F. Tasnádi, M. Odén, I.A. Abrikosov, Ab initio elastic tensor of cubic $\mathrm{Ti}_{0.5} \mathrm{Al}_{0.5} \mathrm{~N}$ alloys: Dependence of elastic constants on size and shape of the supercell model and their convergence, Phys. Rev. B. 85 (2012) 144112.

[35] T. Lee, K. Ohmori, C.-S. Shin, D.G. Cahill, I. Petrov, J.E. Greene, Elastic constants of single-crystal $\operatorname{TiN}_{x}(001)(0.67 \leqslant x \leqslant 1.0)$ determined as a function of $x$ by picosecond ultrasonic measurements, Phys. Rev. B. 71 (2005) 144106.

[36] Q. Yang, L.R. Zhao, P.C. Patnaik, X.T. Zeng, Wear resistant TiMoN coatings deposited by magnetron sputtering, Wear. 261 (2006) 119-125.

[37] G.M. Matenoglou, L.E. Koutsokeras, C.E. Lekka, G. Abadias, C. Kosmidis, G.A. Evangelakis, et al., Structure, stability and bonding of ternary transition metal nitrides, Surf. Coat. Technol. 204 (2009) 911-914. 
[38] R. Sanjinés, C. Wiemer, J. Almeida, F. Lévy, Valence band photoemission study of the Ti-Mo-N system, Thin Solid Films. 290-291 (1996) 334-338.

[39] A.V. Ruban, I.A. Abrikosov, Configurational thermodynamics of alloys from first principles: effective cluster interactions, Rep. Prog. Phys. 71 (2008) 046501.

[40] A. Cavaleiro, C. Louro, J.V. Fernandes, C.M.A. Brett, Use of ultramicroindentation to evaluate the degradation of sputtered coatings, Vacuum. 52 (1999) 157-162.

[41] H. Niu, X.-Q. Chen, P. Liu, W. Xing, X. Cheng, D. Li, et al., Extra-electron induced covalent strengthening and generalization of intrinsic ductile-to-brittle criterion, Sci. Rep. 2 (2012).

[42] S.F. Pugh, XCII. Relations between the elastic moduli and the plastic properties of polycrystalline pure metals, Philos. Mag. Ser. 7.45 (1954) 823-843.

[43] D.G. Pettifor, Theoretical predictions of structure and related properties of intermetallics, Mater. Sci. Technol. 8 (1992) 345-349. 
Table 1. Calculated formation energies and lattice constants of studied structures. Experimental lattice constants are included for comparison.

\begin{tabular}{|c|c|c|c|}
\hline & \multicolumn{2}{|c|}{ Formation energy (eV/atom) } & \multirow{2}{*}{$\begin{array}{c}\text { Average } \\
\text { lattice constant } a(\AA)\end{array}$} \\
\hline & B1 Ti(V)N - B1 W(Mo)N & B1 Ti(V)N - hex W(Mo)N & \\
\hline $\mathrm{V}_{0.5} \mathrm{~W}_{0.5} \mathrm{~N}$ & & & \\
\hline C\#1 & -0.042 & 0.162 & 4.254 \\
\hline $\mathrm{C \# 3}$ & -0.051 & 0.152 & 4.247 \\
\hline $\mathrm{CuPt}$ & -0.062 & 0.141 & 4.242 \\
\hline Random & -0.184 & 0.019 & 4.253 \\
\hline SQS & -0.193 & 0.010 & 4.259 \\
\hline Experiments & - & - & $4.19-4.21^{\mathrm{a}}$ \\
\hline $\mathrm{V}_{0.5} \mathrm{Mo}_{0.5} \mathrm{~N}$ & & & \\
\hline $\mathrm{C} \# 1$ & 0.021 & 0.179 & 4.253 \\
\hline $\mathrm{C \# 3}$ & -0.015 & 0.143 & 4.241 \\
\hline $\mathrm{CuPt}$ & -0.019 & 0.139 & 4.240 \\
\hline Random & -0.113 & 0.045 & 4.247 \\
\hline SQS & -0.122 & 0.037 & 4.252 \\
\hline Experiments & - & - & $4.18-4.20^{\mathrm{b}}$ \\
\hline $\mathrm{Ti}_{0.5} \mathrm{~W}_{0.5} \mathrm{~N}$ & & & \\
\hline $\mathrm{C \# 1}$ & -0.074 & 0.130 & 4.295 \\
\hline $\mathrm{C \# 3}$ & -0.096 & 0.107 & 4.294 \\
\hline $\mathrm{CuPt}$ & -0.099 & 0.105 & 4.299 \\
\hline Random & -0.157 & 0.047 & 4.306 \\
\hline SQS & -0.159 & 0.044 & 4.307 \\
\hline Experiments & - & - & $4.25^{\mathrm{c}}, 4.28^{\mathrm{d}}$ \\
\hline $\mathrm{Ti}_{0.5} \mathrm{Mo}_{0.5} \mathrm{~N}$ & & & \\
\hline $\mathrm{C} \# 1$ & -0.025 & 0.133 & 4.296 \\
\hline $\mathrm{C \# 3}$ & -0.053 & 0.105 & 4.292 \\
\hline $\mathrm{CuPt}$ & -0.057 & 0.102 & 4.298 \\
\hline Random & -0.099 & 0.059 & 4.304 \\
\hline SQS & -0.104 & 0.054 & 4.307 \\
\hline Experiments & - & - & $4.25^{\mathrm{e}}, 4.33^{\mathrm{d}}$ \\
\hline
\end{tabular}

${ }^{a}$ Ref. [21]

${ }^{\mathrm{b}}$ Ref. [19]

${ }^{\mathrm{c}}$ Ref. [24]

${ }^{\mathrm{d}}$ Ref. [37]

${ }^{\mathrm{e}}$ Ref. [38] 
Table 2. Calculated energy per atom of reference binaries.

\begin{tabular}{|r|c|c|}
\hline & \multicolumn{2}{|c|}{ Energy/atom (eV/atom) } \\
\cline { 2 - 3 } & B1 & Hexagonal (WC structure) \\
\hline VN & -9.620 & - \\
TiN & -9.763 & - \\
MoN & -9.651 & -9.968 \\
WN & -10.367 & -10.774 \\
\hline
\end{tabular}


Table 3. Calculated elastic properties of VWN alloys.

\begin{tabular}{|c|c|c|c|c|c|c|c|c|c|c|c|c|c|c|c|c|c|}
\hline & \multirow{2}{*}{$\begin{array}{c}\text { Atomic } \\
\text { arrangement }\end{array}$} & \multirow{2}{*}{$\begin{array}{c}B \\
(\mathrm{GPa})\end{array}$} & \multicolumn{3}{|c|}{$\begin{array}{c}E \\
(\mathrm{GPa})\end{array}$} & \multicolumn{3}{|c|}{$\begin{array}{c}G \\
(\mathrm{GPa})\end{array}$} & \multicolumn{3}{|c|}{$v$} & \multirow{2}{*}{$\begin{array}{c}\bar{C}_{44} \\
(\mathrm{GPa})\end{array}$} & \multirow{2}{*}{$\begin{array}{c}\bar{C}_{11} \\
(\mathrm{GPa})\end{array}$} & \multirow{2}{*}{$\begin{array}{c}\bar{C}_{12} \\
(\mathrm{GPa})\end{array}$} & \multirow{2}{*}{$\begin{array}{c}\bar{C}_{12}-\bar{C}_{44} \\
(\mathrm{GPa})\end{array}$} & \multirow{2}{*}{$G_{h} / B$} & \multirow[t]{2}{*}{$A$} \\
\hline & & & $E_{v}$ & $E_{r}$ & $E_{h}$ & $G_{v}$ & $G_{r}$ & $G_{h}$ & $v_{v}$ & $v_{r}$ & $v_{h}$ & & & & & & \\
\hline $\mathbf{V N}$ & B1 & 320 & 479 & 439 & 459 & 191 & 172 & 182 & 0.334 & 0.348 & 0.341 & 139 & 680 & 140 & 1 & 0.569 & 0.515 \\
\hline$V_{16} W_{16} N_{32}$ & C\#1 & 354 & 308 & 242 & 275 & 114 & 87 & 100 & 0.403 & 0.424 & 0.414 & 64 & 604 & 229 & 165 & 0.284 & 0.266 \\
\hline$V_{16} W_{16} N_{32}$ & $\mathrm{C \# 3}$ & 338 & 342 & 239 & 290 & 128 & 86 & 107 & 0.388 & 0.422 & 0.405 & 61 & 644 & 185 & 124 & 0.318 & 0.343 \\
\hline$V_{16} W_{16} N_{32}$ & $\mathrm{CuPt}$ & 348 & 380 & 259 & 319 & 144 & 94 & 119 & 0.379 & 0.417 & 0.398 & 66 & 696 & 174 & 108 & 0.342 & 0.253 \\
\hline$V_{16} W_{16} N_{32}$ & Random & 315 & 305 & 294 & 300 & 114 & 110 & 112 & 0.392 & 0.396 & 0.394 & 95 & 506 & 220 & 125 & 0.355 & 0.661 \\
\hline$V_{32} W_{32} N_{64}$ & SQS & 313 & 323 & 306 & 315 & 122 & 115 & 118 & 0.385 & 0.391 & 0.388 & 96 & 526 & 207 & 110 & 0.377 & 0.603 \\
\hline
\end{tabular}


Table 4. Calculated elastic properties of VMoN alloys.

\begin{tabular}{|c|c|c|c|c|c|c|c|c|c|c|c|c|c|c|c|c|c|}
\hline & \multirow{2}{*}{$\begin{array}{c}\text { Atomic } \\
\text { arrangement }\end{array}$} & \multirow{2}{*}{$\begin{array}{c}B \\
(\mathrm{GPa})\end{array}$} & \multicolumn{3}{|c|}{$\begin{array}{c}E \\
(\mathrm{GPa}) \\
\end{array}$} & \multicolumn{3}{|c|}{$\begin{array}{c}G \\
(\mathrm{GPa})\end{array}$} & \multicolumn{3}{|c|}{$v$} & \multirow{2}{*}{$\begin{array}{c}\bar{C}_{44} \\
(\mathrm{GPa})\end{array}$} & \multirow{2}{*}{$\begin{array}{c}\bar{C}_{11} \\
(\mathrm{GPa})\end{array}$} & \multirow{2}{*}{$\begin{array}{c}\bar{C}_{12} \\
(\mathrm{GPa})\end{array}$} & \multirow{2}{*}{$\begin{array}{c}\bar{C}_{12}-\bar{C}_{44} \\
(\mathrm{GPa})\end{array}$} & \multirow[t]{2}{*}{$G_{h} / B$} & \multirow[t]{2}{*}{$A$} \\
\hline & & & $E_{v}$ & $E_{r}$ & $E_{h}$ & $G_{v}$ & $G_{r}$ & $G_{h}$ & $v_{v}$ & $v_{r}$ & $v_{h}$ & & & & & & \\
\hline $\mathbf{V N}$ & B1 & 320 & 479 & 439 & 459 & 191 & 172 & 182 & 0.334 & 0.348 & 0.341 & 139 & 680 & 140 & 1 & 0.569 & 0.515 \\
\hline $\mathrm{V}_{16} \mathrm{Mo16}_{32}$ & C\#1 & 334 & 290 & 254 & 272 & 107 & 92 & 100 & 0.404 & 0.416 & 0.410 & 72 & 546 & 228 & 156 & 0.299 & 0.455 \\
\hline $\mathrm{V}_{16} \mathrm{Mo}_{16} \mathrm{~N}_{32}$ & $\mathbf{C \# 3}$ & 335 & 352 & 270 & 311 & 133 & 99 & 116 & 0.383 & 0.410 & 0.397 & 72 & 634 & 185 & 113 & 0.346 & 0.321 \\
\hline $\mathrm{V}_{16} \mathrm{Mo}_{16} \mathrm{~N}_{32}$ & CuPt & 335 & 277 & 176 & 227 & 102 & 62 & 82 & 0.408 & 0.442 & 0.425 & 43 & 588 & 208 & 165 & 0.245 & 0.226 \\
\hline $\mathrm{V}_{16} \mathrm{Mo16}_{32}$ & Random & 300 & 301 & 292 & 296 & 113 & 109 & 111 & 0.389 & 0.392 & 0.390 & 95 & 485 & 207 & 112 & 0.370 & 0.686 \\
\hline $\mathrm{V}_{32} \mathrm{Mos}_{2} \mathrm{~N}_{64}$ & SQS & 296 & 281 & 274 & 278 & 105 & 102 & 103 & 0.394 & 0.397 & 0.396 & 90 & 465 & 212 & 121 & 0.349 & 0.714 \\
\hline
\end{tabular}


Table 5. Calculated elastic properties of TiWN alloys.

\begin{tabular}{|c|c|c|c|c|c|c|c|c|c|c|c|c|c|c|c|c|c|}
\hline & \multirow{2}{*}{$\begin{array}{c}\text { Atomic } \\
\text { arrangement }\end{array}$} & \multirow{2}{*}{$\begin{array}{c}B \\
(\mathrm{GPa})\end{array}$} & \multicolumn{3}{|c|}{$\begin{array}{c}E \\
(\mathrm{GPa})\end{array}$} & \multicolumn{3}{|c|}{$\begin{array}{c}G \\
(\mathrm{GPa})\end{array}$} & \multicolumn{3}{|c|}{$v$} & \multirow{2}{*}{$\begin{array}{c}\bar{C}_{44} \\
(\mathrm{GPa})\end{array}$} & \multirow{2}{*}{$\begin{array}{c}\bar{C}_{11} \\
(\mathrm{GPa})\end{array}$} & \multirow{2}{*}{$\begin{array}{c}\bar{C}_{12} \\
(\mathrm{GPa})\end{array}$} & \multirow{2}{*}{$\begin{array}{c}\bar{C}_{12}-\bar{C}_{44} \\
(\mathrm{GPa})\end{array}$} & \multirow[t]{2}{*}{$G_{h} / B$} & \multirow[t]{2}{*}{$A$} \\
\hline & & & $E_{v}$ & $E_{r}$ & $E_{h}$ & $G_{v}$ & $G_{r}$ & $G_{h}$ & $v_{v}$ & $v_{r}$ & $v_{h}$ & & & & & & \\
\hline TiN & B1 & 290 & 489 & 465 & 477 & 200 & 189 & 195 & 0.313 & 0.322 & 0.317 & 159 & 640 & 115 & -44 & 0.671 & 0.606 \\
\hline $\mathbf{T i}_{16} W_{16} \mathbf{N}_{32}$ & $\mathrm{C \# 1}$ & 343 & 431 & 329 & 380 & 167 & 123 & 145 & 0.361 & 0.393 & 0.377 & 89 & 721 & 154 & 65 & 0.422 & 0.314 \\
\hline $\mathbf{T i}_{16} \mathrm{~W}_{16} \mathrm{~N}_{32}$ & $\mathrm{C \# 3}$ & 338 & 407 & 291 & 349 & 157 & 107 & 132 & 0.366 & 0.404 & 0.385 & 76 & 708 & 153 & 77 & 0.390 & 0.274 \\
\hline $\mathbf{T i}_{16} W_{16} N_{32}$ & $\mathrm{CuPt}$ & 332 & 395 & 296 & 345 & 152 & 110 & 131 & 0.368 & 0.401 & 0.384 & 79 & 679 & 158 & 79 & 0.393 & 0.303 \\
\hline $\mathbf{T i}_{16} W_{16} N_{32}$ & Random & 319 & 332 & 319 & 325 & 125 & 120 & 122 & 0.384 & 0.389 & 0.387 & 103 & 531 & 213 & 110 & 0.384 & 0.646 \\
\hline $\mathbf{T i}_{32} \mathbf{W}_{32} \mathbf{N}_{6}$ & SQS & 315 & 336 & 320 & 328 & 127 & 120 & 124 & 0.382 & 0.387 & 0.384 & 102 & 534 & 206 & 103 & 0.393 & 0.624 \\
\hline
\end{tabular}


Table 6. Calculated elastic properties of TiMoN alloys.

\begin{tabular}{|c|c|c|c|c|c|c|c|c|c|c|c|c|c|c|c|c|c|}
\hline & \multirow{2}{*}{$\begin{array}{c}\text { Atomic } \\
\text { arrangement }\end{array}$} & \multirow{2}{*}{$\begin{array}{c}B \\
(\mathrm{GPa})\end{array}$} & \multicolumn{3}{|c|}{$\begin{array}{c}E \\
(\mathrm{GPa})\end{array}$} & \multicolumn{3}{|c|}{$\begin{array}{c}G \\
(\mathrm{GPa})\end{array}$} & \multicolumn{3}{|c|}{$v$} & \multirow{2}{*}{$\begin{array}{c}\bar{C}_{44} \\
(\mathrm{GPa})\end{array}$} & \multirow{2}{*}{$\begin{array}{c}\bar{C}_{11} \\
(\mathrm{GPa})\end{array}$} & \multirow{2}{*}{$\begin{array}{c}\bar{C}_{12} \\
(\mathrm{GPa})\end{array}$} & \multirow{2}{*}{$\begin{array}{c}\bar{C}_{12}-\bar{C}_{44} \\
\quad(\mathrm{GPa})\end{array}$} & \multirow{2}{*}{$G_{h} / B$} & \multirow[t]{2}{*}{$A$} \\
\hline & & & $E_{v}$ & $E_{r}$ & $E_{h}$ & $\overline{G_{v}}$ & $G_{r}$ & $G_{h}$ & $v_{v}$ & $v_{r}$ & $v_{h}$ & & & & & & \\
\hline TiN & B1 & 290 & 489 & 465 & 477 & 200 & 189 & 195 & 0.313 & 0.322 & 0.317 & 159 & 640 & 115 & -44 & 0.671 & 0.606 \\
\hline $\mathrm{Ti}_{16} \mathrm{Mo}_{16} \mathbf{N}_{32}$ & $\mathrm{C \# 1}$ & 326 & 410 & 332 & 371 & 159 & 125 & 142 & 0.360 & 0.387 & 0.373 & 93 & 670 & 154 & 61 & 0.435 & 0.361 \\
\hline $\mathrm{Ti}_{16} \mathrm{Mo}_{16} \mathbf{N}_{32}$ & C\#3 & 327 & 397 & 323 & 360 & 153 & 121 & 137 & 0.365 & 0.390 & 0.378 & 90 & 657 & 162 & 72 & 0.419 & 0.364 \\
\hline $\mathrm{Ti}_{16} \mathrm{Mo16}_{32}$ & CuPt & 322 & 406 & 346 & 376 & 158 & 131 & 144 & 0.360 & 0.381 & 0.370 & 100 & 647 & 159 & 59 & 0.448 & 0.410 \\
\hline $\mathrm{Ti}_{16} \mathrm{Mo16}_{32}$ & Random & 299 & 354 & 337 & 346 & 136 & 128 & 132 & 0.368 & 0.375 & 0.372 & 109 & 535 & 181 & 72 & 0.442 & 0.615 \\
\hline $\mathrm{Ti}_{32} \mathrm{Mo}_{32} \mathrm{~N}_{64}$ & SQS & 301 & 353 & 334 & 343 & 135 & 127 & 131 & 0.370 & 0.377 & 0.373 & 106 & 539 & 182 & 76 & 0.435 & 0.595 \\
\hline
\end{tabular}


Table 7. Comparison of calculated Young's moduli values with experimental results from alloys of similar composition. Calculated values span Reuss, Voigt and Hill averages.

\begin{tabular}{|l|l|l|}
\hline & \multicolumn{2}{|c|}{ Young's modulus E (GPa) } \\
\hline & calculated & experimental \\
\hline $\mathrm{V}_{0.5} \mathrm{~W}_{0.5} \mathrm{~N}$ & $239-380$ & $353-376^{\mathrm{a}}$ \\
$\mathrm{V}_{0.5} \mathrm{Mo}_{0.5} \mathrm{~N}$ & $176-352$ & $265-370^{\mathrm{b}}$ \\
$\mathrm{Ti}_{0.5} \mathrm{~W}_{0.5} \mathrm{~N}$ & $291-431$ & $293-384^{\mathrm{c}}$ \\
$\mathrm{Ti}_{0.5} \mathrm{Mo}_{0.5} \mathrm{~N}$ & $323-410$ & $332-344^{\mathrm{d}}$ \\
\hline
\end{tabular}

${ }^{a} \operatorname{Ref} 21$

${ }^{\mathrm{b}} \operatorname{Ref} 19$

${ }^{\mathrm{c}} \operatorname{Ref} 40$

${ }^{\mathrm{d}} \operatorname{Ref} 36$ 